\title{
LIGHTWEIGHT SELF-COMPACTING CONCRETE USING LIGHTWEIGHT EXPANDED CLAY AGGREGATE
}

\author{
SARAB AMIR AL-JUBORI ${ }^{1}$, JINAN JAWAD HASSAN ALWASH ${ }^{2}$ \& RAFEA FLAIH HASSAN ${ }^{3}$ \\ $1{ }^{*}$ Graduate Research Student, College of Engineering, University of Babylon, Iraq \\ ${ }^{2 \& 3}$ College of Engineering, University of Babylon, Iraq
}

\begin{abstract}
The aim of the research is to find out the performance of lightweight self-compacting concrete (LWSCC) made with $(25 \%, 50 \%, 75 \%, 100 \%)$ lightweight expanded clay aggregate (LECA) as replacement percentage by volume of natural weight coarse aggregate. Ten mixes were made, five of them contain (LECA) with $(25 \%, 50 \%, 75 \%$ and100\%) and without fibre. The other five mixes contain (LECA) with the same percentages and with $(0.1 \%)$ polypropylene fibre. The characteristics of hardened and fresh were checked by series of testing methods including UPV test, water absorption, flexural strength, splitting tensile strength, compressive strength, fresh density, $V$-funnel, $T_{50 \mathrm{~cm}} L-b o x$, and slump flow. The slump flow for all mixes was kept at $(665-731) \mathrm{mm}$; the results showed that the fresh density of LWSCC was varied from 1956- $2475 \mathrm{~kg} / \mathrm{m}^{3}$, which decline with increasing LECA content. With increasing the percentage of LECA, the V-funnel flow time was increased while $T_{50}$ decreased, while they increased when polypropylene fibre is used. The results also demonstrated that flexural strength, splitting tensile strength and compressive strength were lower when increase the percent of LECA, and generally enhanced as the fibre used. The water absorption was increased, and dry density was reduced with increasing the percent of LECA. This increase is reduced slightly by adding fibre at the same time, and it has no apparent effect on the dry density.
\end{abstract}

KEYWORDS: Lightweight, Self-Compacted, Expanded Clay Aggregate, LWSCC, LECA

Received: Jun 08, 2020; Accepted: Jun 28, 2020; Published: Sep 18, 2020; Paper Id.: IJMPERDJUN20201335

\section{INTRODUCTION}

Self-compacting lightweight concrete combines the positive characteristics of SCC of high flowability and LWC. The basic criteria required to achieve LWSCC are resistant against segregation, high passing ability, or high deformability. The lightweight expanded clay is appropriate for using in LWSCC by reason of spherical shape enhancing rheological characteristics of fresh concrete mixture, also it could be affected on the increasing of LWSCC compressive strength [1-4]. Different testing methods used for LWSCC are similar to those used for selfcompacting normal weight concrete (SCNWC). When combined with the L-box test, the slump flow test is very appropriate for controlling the quality on-site SCC [5]. It is believed that strength and durability are associated with hardened concrete, and the workability is associated to the fresh concrete. Still, the hardened characteristics can be directly attributed to the mix design and fresh characteristics $[6,7]$. In general, the compressive strength of LWSCC is a key parameter for estimating its other mechanical characteristics [8]. In most previous work, the reported 28day compressive strength for LWSCC values ranged from 14 to $58 \mathrm{MPa}$, with about $34 \%$ of mixtures having a strength greater than $40 \mathrm{MPa}$ and $53 \%$ exceeding (32 MPa) $[9,10]$. 
LWSCC was already utilized in structural applications, especially in large bridge structures owing to its less noise level on location, light self-weight, simplicity of construction, etc. Coarse LWSCC aggregates have included expanded polystyrene [11], pumice [12], expanded clay ceramist [13], expanded shale [14], and so on. All used coarse aggregates are so lightweight as to be able to float in paste of cement. LWSCC needs great fluidity. Hence it is necessary to decrease the viscosity and plasticity of fresh putty. Then, the segregation is increased, so it is necessary for LWSCC to design a reasonable mix ratios

\section{INVESTIGATIONAL WORK}

\subsection{Components}

\section{A) Cement}

In this work, Portland limestone cement (PLC), which was manufactured by Lafarge, was used.

B) Sand

In this project, natural sand was used from the Al-Ukhaider zone, its specific gravity (2.6) and its maximum size (4.75 $\mathrm{mm}$ ). The grades used are within a zone (2) according to the basic specifications of the Iraqi Standard (No. 45/1984) [15]. An examination was made at the Construction Materials Laboratory at the University of Babylon

\section{C) Coarse Aggregate}

Round gravel with a max size $1 \mathrm{~cm}$ and a specific gravity 2.65 from AL-Niba'ee quarry was used as coarse aggregates in prepared mixtures. The physical characteristics and grading have been classified according to the basic specifications of Iraqi Standard No. (45/1984)[15]. An examination was made at the Construction Materials Laboratory at the University of Babylon.

\section{D) Lightweight Aggregate}

Lightweight expanded clay from "Leca" company was used as a lightweight coarse aggregate in this project. Round shape with a $1 \mathrm{~cm}$ as a max size was used. It has low weight, low thermal conductivity, sound low stability and stability. The mean bulk density of LECA was (290) $\mathrm{kg} / \mathrm{m}^{3}$. The mixed aggregate (LECA + NCA) was examined by sieving analysis for use in this work according to IQS Standard No. $\mathbf{4 5 / 1 9 8 4}$ for the specifications of coarse aggregate.

\section{E) Micro Silica Fume (SF)}

Micro silica fumes are utilized to advance the durability of self-compacting concrete, which is recognized as condensed silica fume is a result of the waste materials of silicon metal or ferrosilicon. It generally contains silicon dioxide (SiO2) highly than $85 \%$ in the form of an amorphous organism (non-crystalline) form. It is a very fine particle with a size less than $1 \mu \mathrm{m}$ and a diameter of about $(0.1 \mu \mathrm{m})$, which is approximately 100 times the minimum cement particle size, and is very effective when used in concrete. Therefore it is suitable for using in tropical and hot climatic environment. It is a grey powder. MS is generally used at $5 \%$ to $15 \%$ by weight of total cement materials [16,17]. MS must meet specifications [18].

It is a white mashed material of limestone extracted specific gravity 2.7 while the specific surface is $789 \mathrm{~m}^{2} / \mathrm{kg}$, the chemical results of limestone powder showed that the ratio of $\mathbf{C a C O}_{3}$ (Min.) is $85 \%, \mathbf{C a O}$ is $45 \%$ and L.O.I was about 40 $\%$. 
G) Polymer Microfibers (Polypropylene)

The main advantage of using fibre in reinforced concrete, it has good resistant to fine cracking, impact and fatigue, as well as its ability to reduce permeability and improve shear strength, tension, flexural and compression [19]. Table 1 shows the characteristics of these fibres that were used throughout the experimental work

Table 1: Polypropylene's fibre Characteristics

\begin{tabular}{|c|c|c|c|c|c|c|c|c|c|c|}
\hline 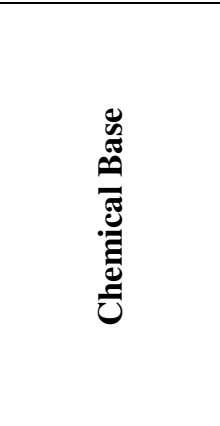 & 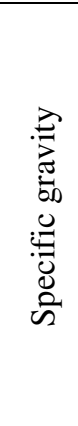 & 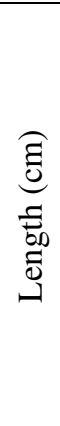 & 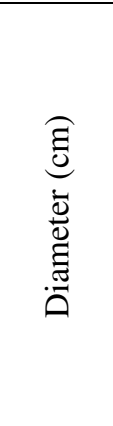 & 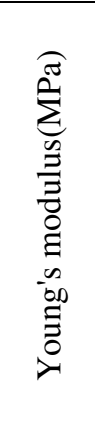 & 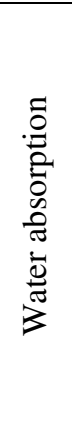 & 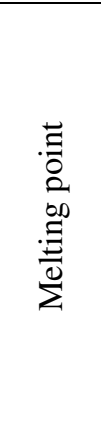 & 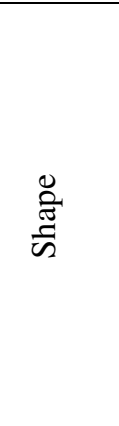 & 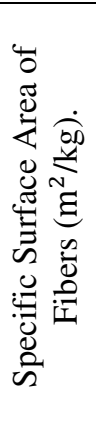 & 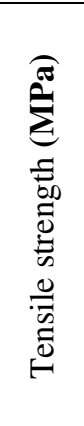 & 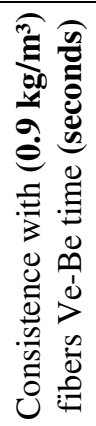 \\
\hline $\begin{array}{c}100 \% \\
\text { Polypropylene } \\
\text { fiber }\end{array}$ & 0.91 & 1.2 & 0.0032 & $\begin{array}{c}3500- \\
3900\end{array}$ & Nill & $160^{\circ} \mathrm{C}$ & straight & 250 & $\begin{array}{l}600- \\
700\end{array}$ & 14 \\
\hline
\end{tabular}

\section{H) High Range Water Reducer}

Sika Vis-Concrete 5930-L superplasticizer has been used, which achieves the specifications of superior plasticizer depending to ASTM-C-494 [20] type F and G. This additives works as a water reducer, which providing excellent flowability at the same time for optimum cohesion and higher concrete with compact capacity. The solution was queues of modified polycarboxylate. The characteristics of the 5930-L concrete utilized in this research are presented in Table 2.

Table 2: Properties of polypropylene fibre

\begin{tabular}{|c|c|c|c|c|}
\hline Properties & Appearance & Basis & Density & Chloride content \\
\hline Value & Turbid liquid & $\begin{array}{c}\text { An aqueous solution of } \\
\text { modified } \\
\text { polycarboxylate }\end{array}$ & $\begin{array}{c}1.1 \mathrm{~kg} / \mathrm{Lit} . \\
\text { (ASTM C494) }\end{array}$ & 0 \\
\hline
\end{tabular}

\section{Concrete Mixture}

This study aims to attain the characteristics of (10) mixes that are separated into two sets. The first set contains (5) mixtures. The first one is a reference mix. The others contain (25, 50, 75 and 100\%) percentages of lightweight aggregate as volume replacing of coarse aggregate. The second group is the same as the first one by all mixes having polypropylene fibre by $(0.1 \%)$ of concrete volume. As demonstrated in Table3, and Table4 shows the details of notation of all mixes. The concrete was designed according to the [21] method. 
Table 3: Trail mixes for control mix design

\begin{tabular}{|c|c|c|c|c|c|c|c|c|c|c|c|}
\hline \multirow[t]{2}{*}{$\begin{array}{l}\text { Set. of } \\
\text { mixes }\end{array}$} & \multicolumn{2}{|c|}{\begin{tabular}{l}
\multicolumn{2}{l}{ Cementitious } \\
Materials (kg \\
$\left./ \mathrm{m}^{3}\right)$
\end{tabular}} & \multirow{2}{*}{ 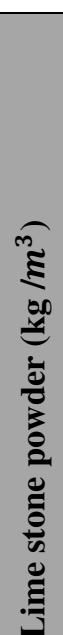 } & \multirow[b]{2}{*}{ 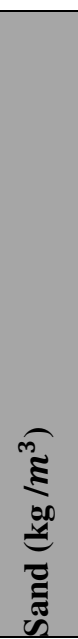 } & \multirow{2}{*}{ 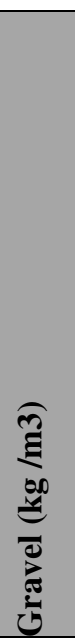 } & \multirow{2}{*}{ 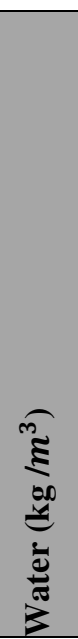 } & \multirow[t]{2}{*}{$W / b$} & \multirow{2}{*}{ 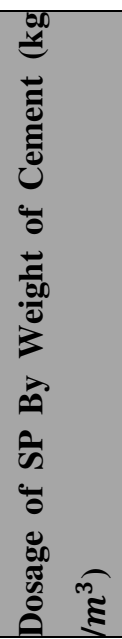 } & \multirow{2}{*}{ 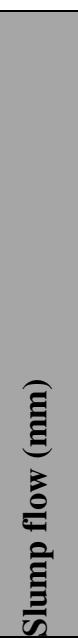 } & 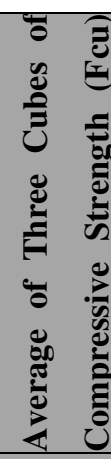 & $\sum^{E}$ \\
\hline & cement & $\begin{array}{l}\text { Silica } \\
\text { fume }\end{array}$ & & & & & & & & 7 day & $\begin{array}{l}28 \\
\text { day }\end{array}$ \\
\hline $\mathrm{A}$ & 432 & 48 & 80 & 815 & 800 & 162 & 0.29 & $\overline{5.4}$ & 615 & 43.2 & 58.6 \\
\hline B & 432 & 48 & 80 & 815 & 800 & 162 & 0.29 & 6.48 & 675 & 50 & 65.14 \\
\hline $\mathrm{C}$ & 432 & 48 & 80 & 815 & 800 & 162 & 0.29 & 6.8 & 730 & 56.046 & 60.52 \\
\hline $\mathrm{D}$ & 432 & 48 & 80 & 815 & 800 & 162 & 0.29 & 8.64 & 800 & ----- & ------ \\
\hline
\end{tabular}

Table 4: Mixes Notation

\begin{tabular}{|c|l|}
\hline Mix notation & \multicolumn{1}{c|}{ Details } \\
\hline \multicolumn{1}{|c|}{$\mathbf{L}_{\mathbf{0}}$} & Reference mix with (0\%) of LECA. \\
\hline $\mathbf{L}_{\mathbf{2 5}}$ & Mix with (25\%) LECA as a natural gravel replacement. \\
\hline $\mathbf{L}_{\mathbf{5 0}}$ & Mix with (50\%) LECA as a natural gravel replacement. \\
\hline $\mathbf{L}_{\mathbf{7 5}}$ & Mix with (75\%) LECA as a natural gravel replacement. \\
\hline $\mathbf{L}_{\mathbf{1 0 0}}$ & Mix with (100\%) LECA as a natural gravel replacement. \\
\hline $\mathbf{P L}_{\mathbf{0}}$ & Mix with(0\%) of LECA and (0.1\%) polypropylene fiber by volume of concrete \\
\hline $\mathbf{P L}_{\mathbf{2 5}}$ & $\begin{array}{l}\text { Mix with (25\%) LECA as a natural gravel replacement and (0.1\%) polypropylene fibre } \\
\text { by concrete volume. }\end{array}$ \\
\hline $\mathbf{P L}_{\mathbf{5 0}}$ & $\begin{array}{l}\text { Mix with (50\%) LECA as a natural gravel replacement and (0.1\%) polypropylene fibre } \\
\text { by concrete volume. }\end{array}$ \\
\hline $\mathbf{P L}_{\mathbf{7 5}}$ & $\begin{array}{l}\text { Mix with (75\%) LECA as a natural gravel replacement and (0.1\%) polypropylene fibre } \\
\text { by concrete volume. }\end{array}$ \\
\hline $\mathbf{P L}_{\mathbf{1 0 0}}$ & $\begin{array}{l}\text { Mix with (100\%) LECA as a natural gravel replacement and (0.1\%) polypropylene } \\
\text { fibre by concrete volume. }\end{array}$ \\
\hline
\end{tabular}

The percentages of the fibres used are the optimum percentage obtained from previous studies [22].

\section{Mixing Procedure}

In this research, the Emborg Report (Emborg, 2000) mixing method was essential to achieving the desired homogeneity and operability of the concrete mixture. SCC is blended in a rotary mixer $\left(0.055 \mathrm{~m}^{3}\right)$. The mixing process was as follows:

- $1 / 3$ of the water and the super-plasticized dose were mixed and added to the fine aggregate that was the mixer first, and mixed for a period of (one minute).

- Another $1 / 3$ of water and a dose of superior plasticizer were used in the mixture with cement and mineral mixture that blended for (0.5 minutes). 
- After that, the last $1 / 3$ of the superplasticizer dose were and water added to half the amount of coarse aggregate and mixing in ( 1 minute), then the mixture was rested for ( 0.5 minutes).

- Finally, half of the remaining amount of coarse aggregate was added to the mixer, so that the time for thorough mixing was (5-7 minutes).

- The mixture is then emptied, poured and cured.

\section{Curing and Casting Procedures of the Samples}

Before casting, the chosen materials were weighed and produced depending on the mixture volume, the high water absorption of LECA causes the slump loss of the fresh mixture. So, LECA was submerged in water for three days. To ensure the saturation of the saturated surface (SSD) as demonstrated in plate 1, samples are cast in a short period to reduce the difference in condition of exposure, the moulds and inner surface are cleaned and oiled to avoid cohesion of hardened concrete on the mould sides. Then the samples are left in the lab for 24 hrs. then de-moulded accurately and soaked in water of curing for 6
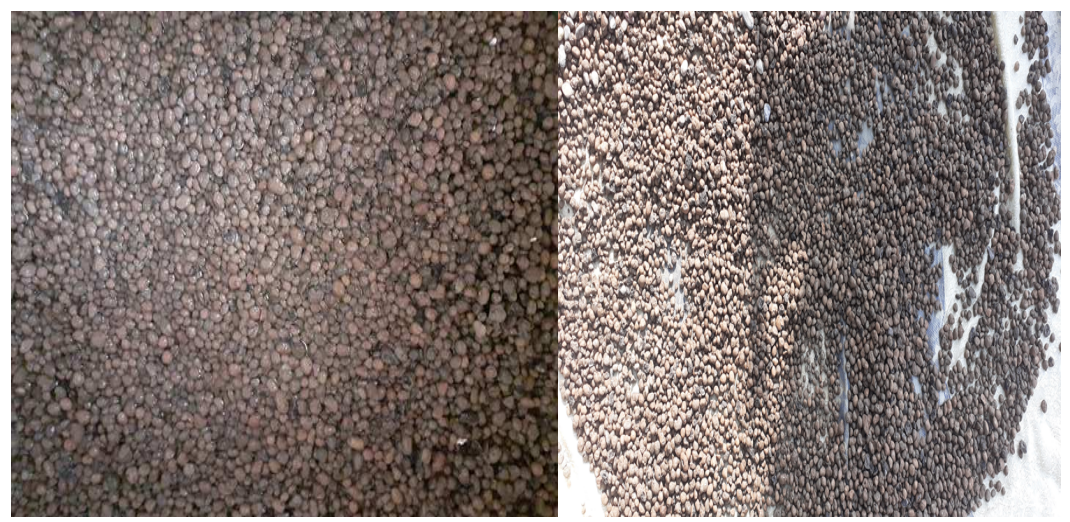

Plate 1: A) LECA submerged in water B) LECA when dried

\section{Tests of Fresh Concrete}

The self-compacting concrete is categorized by high flowability so that the traditional procedure to measure the workability cannot be used for this property. Many researchers and agencies use L-box test, V- funnel test, and slump flow test, $T_{500} \mathrm{~mm}$ test as test method ways for SCC's workability and viscosity characteristics. These ethics are given in the European Federation dedicated to specialized chemical construction materials and concrete systems SCC guidelines.

\section{Hardened Tests of Concrete}

\subsection{Compressive Strength}

With each combination, three cubes $(10 \times 10 \times 10 \mathrm{~cm})$ were cast to evaluate the compressive power, and the average value of such cubes was obtained under (ASTM C109 / C109M) [23]. The compressive strength test was measured by destroying three cubes in curing ages (7 and 28 days) with a capacity of digital measuring system $(1900 \mathrm{kN})$, loading at a rate $(0.3 \mathrm{MPa} / \mathrm{s})$ was applied.

\subsection{Splitting Tensile Strength}

The split tensile strength of the concrete has been standardized with the specifications (ASTM C496) [24]. Three 
cylindrical concrete samples $(100 \times 200 \mathrm{~mm})$ were implemented for each mixture, and curing ages ( 7 and 28 days). Two bearing strips loaded with a thickness of $0.3 \mathrm{~cm}$ of plywood, a width of $2.5 \mathrm{~cm}$ and a length of $20 \mathrm{~cm}$ were sited under and above the sample that was located between the blocks bearing of the testing machine, an electric testing machine with a capacity of $1900 \mathrm{kN}$.

\subsection{Modulus of Rupture}

The concrete modulus of rupture was identified by testing prism specimens (100 x $100 \times 400 \mathrm{~mm}$ ) according to (ASTM C78) [25]. The two prisms were certified in each test case. It was calculated with a clear span supported by (300) $\mathrm{mm}$. Each prism is simply supported and subjected to a two-point load using a test machine with a capacity $(1900 \mathrm{kN})$.

\subsection{Dry Density Test}

The dry density of concrete was conducted depending on (ASTM C1754 / C1754M) [26]. The following formula identified the dry density of (3) specimens cubes of concrete: Firstly, the concrete samples were dried at $100 \pm 2{ }^{0} \mathrm{C}$ for 24 hrs. Then they were weighed to the nearest $10.1 \mathrm{~g}$. $\mathrm{W}_{0}$

$\rho_{\mathrm{dry}}=\frac{W}{V}$

$\rho_{\text {dry }}=$ dry density of concrete $\left(\mathrm{Kg} / \mathrm{m}^{3}\right)$

$\mathrm{W}_{0}=$ dry weight $(\mathrm{Kg}), \mathrm{V}=$ volume $\left(\mathrm{m}^{3}\right)$

\subsection{Total Absorption Test for Concrete}

Measurement was conducted on $(10 * 10) \mathrm{cm}$ cubes according to ASTM C642-97 [27]. Firstly; the samples are weighted, and then dried in a kiln at a heat of $100-110^{\circ} \mathrm{C}$ for a period of 24 hours after that, they were taken out from the kiln and reweighed then, the samples were soaked in water at a temperature about $21^{\circ} \mathrm{C}$ for 48 hours. After that surface was dried and weighed.

\subsection{Ultrasonic Pulse Velocity test (U.P.V.)}

Ultrasonic pulse velocity test was done depending on (ASTM C597) [28]. This technique is mainly dependent on the propagation of high-frequency sound waves that transit through solid material utilizing portable equipment (PUNDIT), consisting of the source/detector unit and surface power transformers, operating in the frequency range from 25 to $60 \mathrm{kHz}$. Ultrasound pulses baseed on the density of the material and its elastic characteristics [29]. Cubes with dimensions (100* 100) $\mathrm{mm}$ were used for this test. The following equation gives the pulse velocity:

$V=\frac{L}{T}$

Whereas:

$\mathrm{V}=$ velocity of pulse $(\mathrm{km} / \mathrm{sec}), \mathrm{L}=$ distance between the centre of transducer faces $(\mathrm{mm}), T=$ time of transit $(\mu \mathrm{sec})$.

\section{RESULTS AND DISCUSSIONS}

\subsection{Fresh characteristics of SCC and LWSCC}

The Fresh characteristics of the concrete mixes were evaluated by the tests and compared with the standard criteria. The workability tests were depended on fresh mixes instantly after mixing including V-funnel, V-funnel, slump flow, T500 at 
Tv after (5) minutes, L-box tests, and fresh density. These tests were carried out according to the European Project Group [21]. The results of these tests are demonstrated in Table 5

Table 5: Workability test results for concrete mixes

\begin{tabular}{|c|c|c|c|c|c|c|}
\hline \multirow[b]{2}{*}{$\begin{array}{l}\text { Types of } \\
\text { mixes }\end{array}$} & \multicolumn{2}{|c|}{ Slump Flow } & \multirow[b]{2}{*}{$\begin{array}{c}\text { L-Box } \\
\text { BR }\end{array}$} & \multicolumn{2}{|c|}{ V-funnel } & \multirow{2}{*}{$\begin{array}{c}\text { Fresh } \\
\text { density }\left(\mathrm{Kg} / \mathrm{m}^{3}\right)\end{array}$} \\
\hline & $\mathrm{D}(\mathbf{m m})$ & $\mathbf{T}_{500}(\mathrm{sec})$ & & $T_{V}(\sec )$ & $\begin{array}{c}\mathrm{T}_{V} \text { at } \\
5 \mathrm{~min}(\mathrm{sec} .)\end{array}$ & \\
\hline $\mathrm{L}_{0}$ & 675 & 5 & 0.92 & 8 & 9 & 2475 \\
\hline $\mathrm{L}_{25}$ & 680 & 4 & 0.93 & 10 & 12 & 2195 \\
\hline $\mathrm{L}_{50}$ & 692 & 4 & 0.935 & 13 & 15 & 2080 \\
\hline $\mathrm{L}_{75}$ & 709 & 3 & 0.94 & 14 & 17 & 2018 \\
\hline $\mathrm{L}_{100}$ & 731 & 3 & 0.96 & 16 & 19 & 1956 \\
\hline $\mathrm{PL}_{0}$ & 665 & 5 & 0.90 & 9 & 10 & 2477 \\
\hline $\mathrm{PL}_{25}$ & 668 & 5 & 0.91 & 11 & 13 & 2193 \\
\hline $\mathrm{PL}_{50}$ & 676 & 4.5 & 0.93 & 14 & 16 & 2078 \\
\hline $\mathrm{PL}_{75}$ & 696 & 3.5 & 0.94 & 15 & 18 & 2017 \\
\hline $\mathrm{PL}_{100}$ & 715 & 3 & 0.947 & 17 & 20 & 1950 \\
\hline
\end{tabular}

\subsection{Hardened characteristics of SCC and LWSCC}

Mechanical characteristics of hardened concrete performed in this investigation consisted of rupture modulus, splitting tensile strength, compressive strength at ages 7 and 28 days, and also UPV, total absorption and dry density tested at the age of 28 days.

\section{A) Compressive strength}

The most popular of all tests on hard concrete is the compressive strength test. It is utilized to calculate concrete's potential strength. The concrete compressive strength characteristic is utilized to categorize the concrete into the national and international codes. The test of compressive strength $\left(f_{\text {cu }}\right)$ was carried out using $(100 \times 100 \times 100) \mathrm{mm}$ cubes cured in tap water at ages of 7 day and 28 days as summarized in Table 6, Figure 1 (A and B)

From Table( 6) it could be observed that the compressive strength decreased with increase the percentage of LECA, the percentage of the declination in compressive strength at (7) days was about $(14.13 \%, 19.92 \%, 28.08 \%, 39.6 \%)$ when the percentage of the LECA replacement were $(25 \%, 50 \%, 75 \%, 100 \%)$ respectively, while at (28)days the percentage of declination were increased to be $(15.83 \%, 25.96 \%, 35.0 \%, 44.72 \%)$ respectively. The main reason for this reduce in compressive strength with the incorporation of LECA is the low density of LECA reduced density of concrete. Respectively the compressive strength decreased, as it was reported that the higher the concrete density with the higher the compressive strength [4,30-32]. LECA form, in most cases, spherical. This figure demonstrated less binding force to the surrounding paste than the angle. Since LECA is a porous material, the fracture that usually occurs in aggregates [33]. It can also be observed that the addition of polypropylene fibres ( $12 \mathrm{~mm}$ in length) slight improvement in 7 and 28 days of compressive strength of LECA-containing concrete (maximum size $10 \mathrm{~mm}$ ) as coarse aggregate by $(0.8-1.8) \%$ and (0.42.2)\% respectively, in comparison with the mixes without PP fibre. Plate2 show SCC with and without polypropylene fibre 


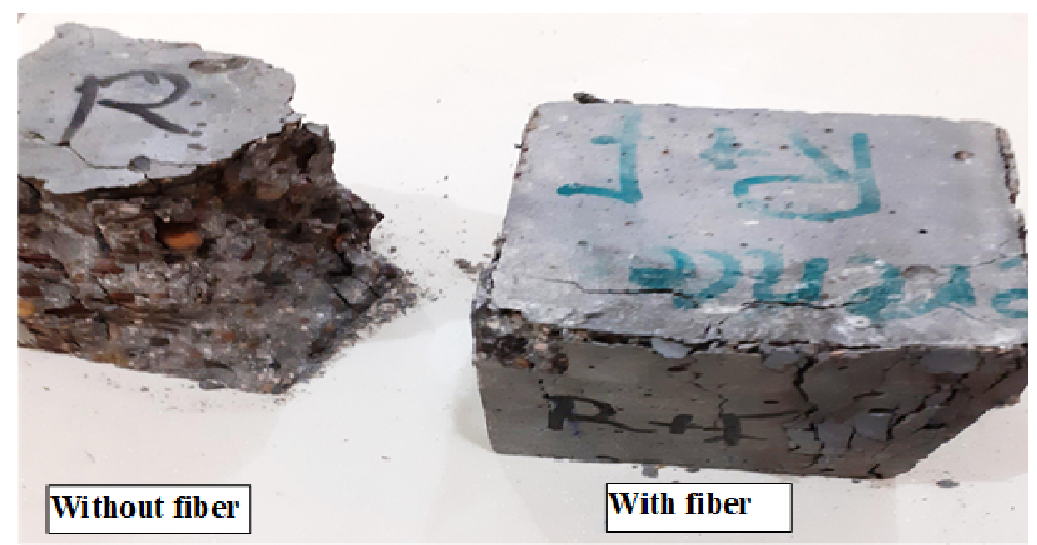

Plate 2: The shape of failure for cube specimens with and without polypropylene fibre
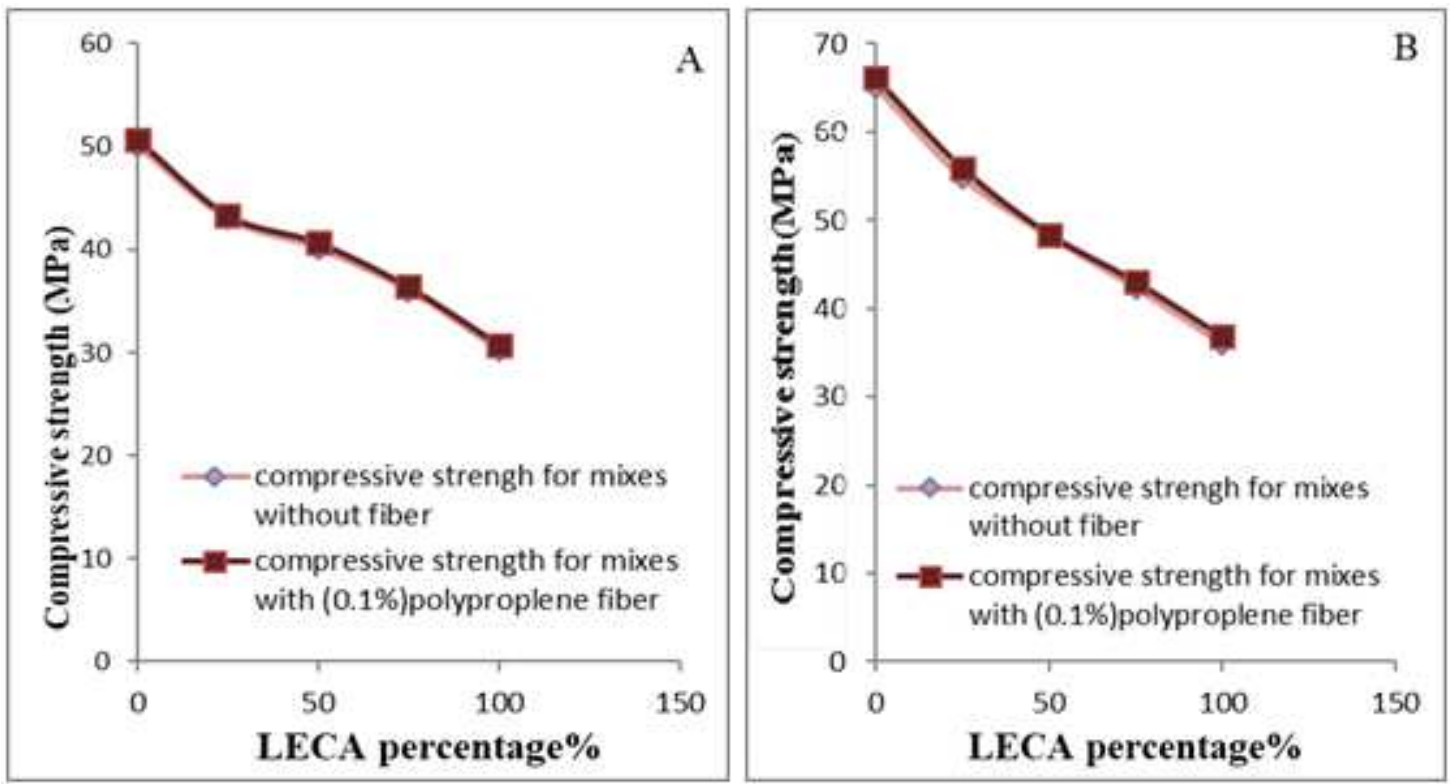

Figure 1: Compressive strength with LECA percentage at A) 7 days and B) 28 days.

\section{B)}

\section{Splitting Tensile Strength}

Table (6) summarizes the values of the split tensile strength (fsp) for the samples examined in this research. The tensile strength governs the cracking behaviour and affects other characteristics such as stiffness and durability of concrete. The split tensile strength was performed using a cylinder with dimensions of (100 x 200) $\mathrm{mm}$ in ages (7 and 28 days), by applying the same procedure used in calculating the compressive strength, three cylinders performed each test.

The results of the splitting tensile strength tests, demonstrated in Table 6, Figure 2 (A and B) show that with LECA replacement increased by percentages $(25,50,7 \%, 100 \%)$ there was a reduce in splitting tensile strength about (25.7, $41.9,46.7,50.7 \%)$ and $(22.9,31.2,36.9,44.4 \%)$ at 7 and 28 days respectively. Also, it can be seen that the addition of $(0.1 \%)$ polypropylene fibre by volume of the concrete increase the splitting tensile strength about $(16.2,14.3,21,18.4$, 16.7) and $(17.2,18.5,18.9,18.3,16.9 \%)$ for 7 and 28 days, respectively in comparison with the mixes without PP fibre. The reduce in the splitting tensile strength with the increase in the percentage of LECA is due to the lower crushing strength, the strength of particles and open voids compared to the normal weight of the aggregate and the lower density [33].while the increase in splitting tensile strength due to adding $(0.1 \%)$ polypropylene fibre is due to viscid behaviour of polypropylene fibre when it adds to SCC. Thus LWA aggregate in SCC mix is modified when they are added to the mix 
[34]. Plate 3 shows SCC with and without PP fibre

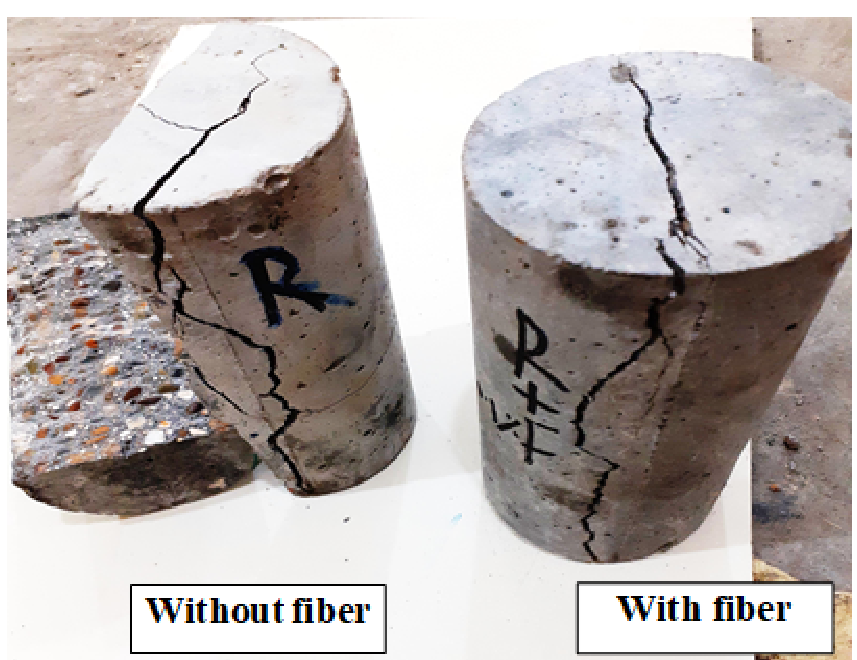

Plate 3: Shape of failure for cylinder specimens with and without polypropylene fibre

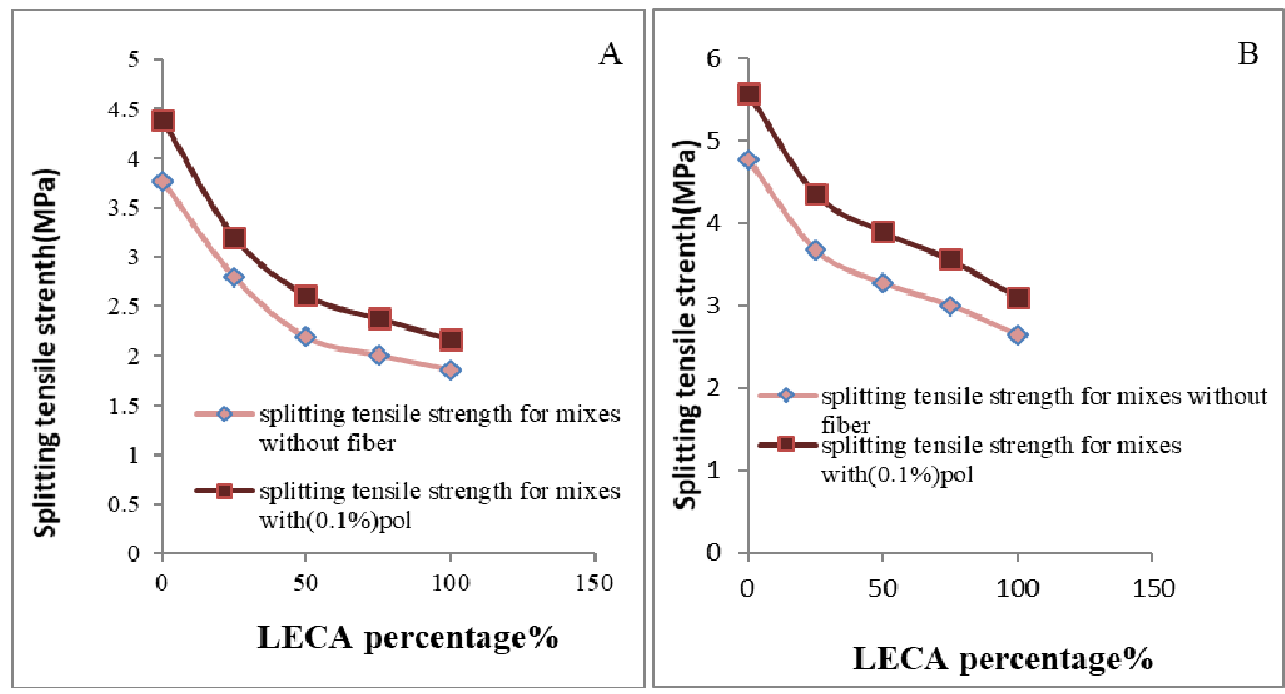

Figure 2: Splitting tensile strength with LECA percentage at A) 7 days and B) 28 days

\subsection{Rupture Modulus (Flexural Strength)}

Rupture modulus of test was utilized to express the flexural strength. Each prism is tested as simply supported and subjected to a 2-point downloading. Table (6) displays the tested results, where each value in this table represents the average value of (3) prismatic samples to reduce the expected error in any measured result.

The same method was observed in the compressive strength and splitting tensile strength in this investigation. It was found that the flexural strength decreased with the increase in the percentage of LECA from (0\%) to (100\%) by $(12.9 \%, 21.6 \%, 30.3 \%, 39.2 \%)$ and $(10 \%, 18.7 \%, 36.3 \%, 41.9 \%)$ at 7 and 28day respectively. It can also be observed that the inclusion of polypropylene fibres in the SCC increases its flexural strength approximately (7.8-10.57\%) in 28 days. The reason for this increase is that after cracking the matrix, polypropylene fibres will carry the load that the concrete bears up to cracking by the interfacial bond between the fibres and the matrix. Therefore, polypropylene fibres resist the spread of cracks and do not suddenly fail, which leads to an increase in the carrying capacity of the load [34]. Figure 3 (A and B) show the relationship between the flexural strength and LECA content at age 7 and 28 days, respectively. 


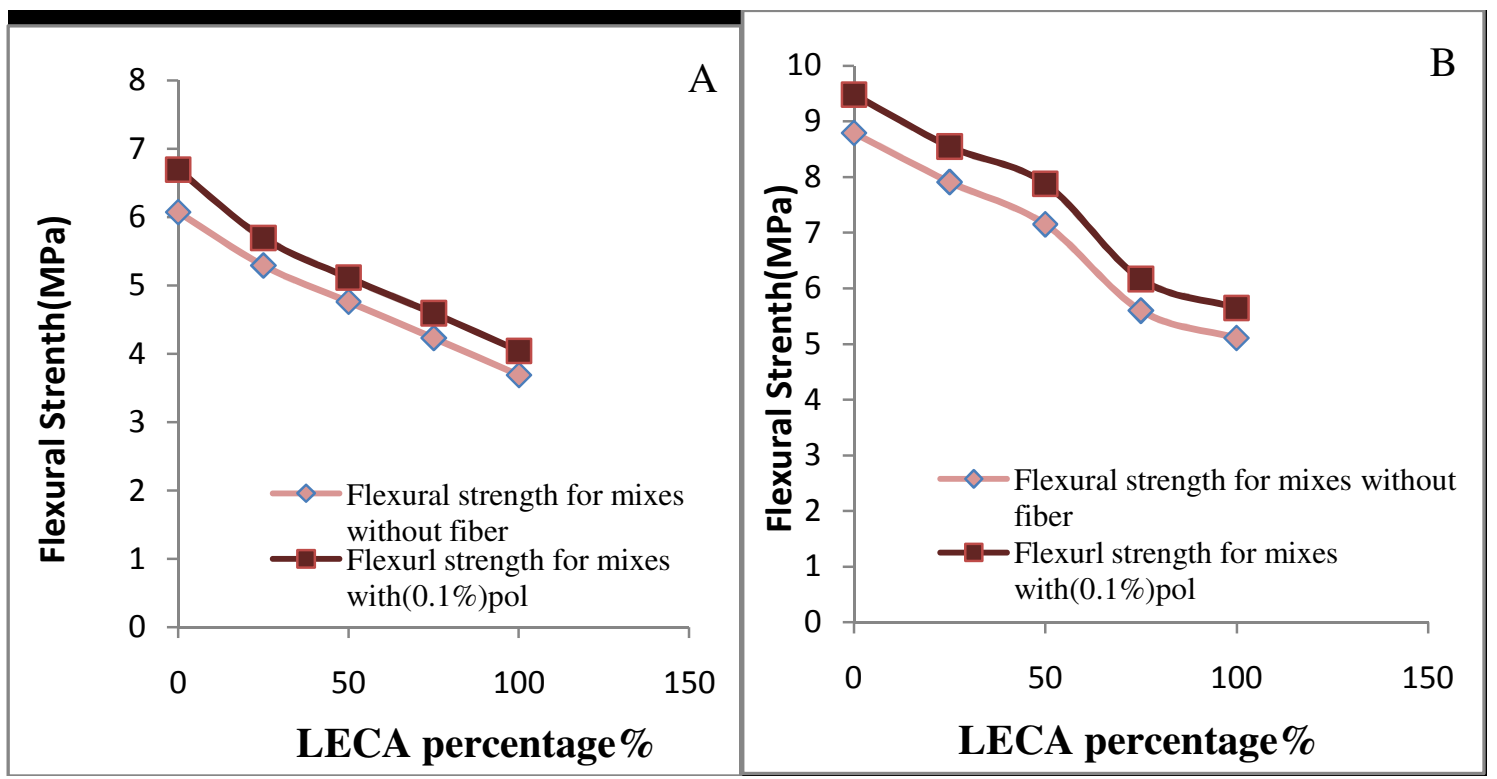

Figure 3: Flexural strength with LECA percentage at A) seven days and B) Twenty-eight days

\section{A) Ultrasonic Pulse Velocity (UPV)}

It is important to assess the UPV values in this research, particularly as they provide concrete density. The results of the test for ultra-pulse velocity (U.P.V.) were determined on $(10 \mathrm{~cm})$ cubes and used to study the variations of ultrasonic pulse velocity of concrete under compression. And cured in water at 28 days.

It could be observed in Table (6) the ultra-sonic pulse velocity was decreased at percentages $(3.9 \%, 6.3 \%, 9.4 \%$, $14.4 \%)$ when LECA replacement was $(25 \%, 50 \%, 75 \%, 100 \%)$ at 28 days respectively, The highly irregular and porous nature of LWA affects wave propagation across samples. The presence of empty voids in the concrete mass and between aggregates decrease the UPV velocity due to hindering the air impact. In the low percent of natural weight coarse aggregate replacement with LECA, the pulse transfer is improved due to the gravel's solid nature that makes the transferring the pulse fast. High density of concreate produced as a result of decreasing the void content to transfer UPV faster. The correlation gained could be utilized to predict strength depending on the values of UPV [35], as demonstrated in Figure 4. Also it could be observed that the adding of polypropylene fiber enhance the UPV result by $(2.2 \%, 1.8 \%, 1.6 \%, 1.4 \%, 1.5 \%)$ at replacement percentage $(25 \%, 50 \%, 75 \%, 100 \%)$ for 28 day, respectively in comparison with the mixes without PP fiber. This is consistent with the researcher's opinion [36] found a similar trend that ultrasonic pulse velocity developed due to the inclusion of fibres. 


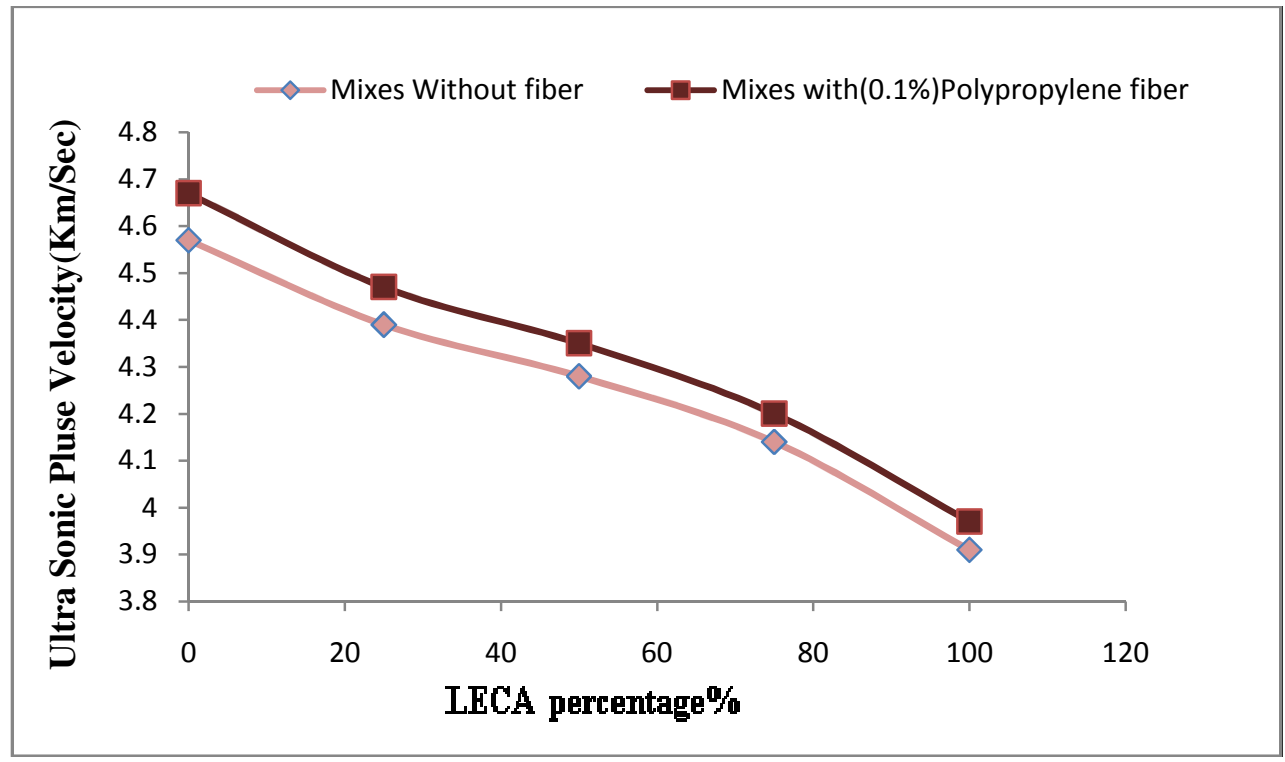

Figure 4: Ultrasonic pulse velocity versus LECA percentage at 28 days

B)

\section{Total Absorption}

The concrete with partial replacement of the natural weight of LECA and coarse aggregate showed greater capillary absorption in both long-term and initial [37], and this phenomenon could be showed in Table (6) for the total absorption results. The results show there was an increase in total absorption with the increase in LECA percentage, the increment is about $(4.1 \%, 22.05 \%, 49.74 \%, 86.67 \%)$ at replacement percentages $(25 \%, 50 \%, 75 \%, 100 \%)$ respectively, at age 28 days, as a result of increased capillary absorption coefficient with increasing LECA content in the mixture [38]. Also, it could be observed that the adding of polypropylene fibres can reduce water absorption by (1.71-2.52) \%. The explanation of this reduction in water permeation was probably attributed to the sewing crack and multiple cracking actions which are provided by reinforcement of fibre for concrete that enhances resistance to water permeation. The permeability of FRSCC minimizes considerably by growing the content of fibre and the time curing period. It is also attributed to the breakage of pores continuity and interconnected passage of porous matrix by the reinforcement of fibre which is confirmed by other studies [39,40]. Figure (5) shows the relationship between total absorption and LECA content

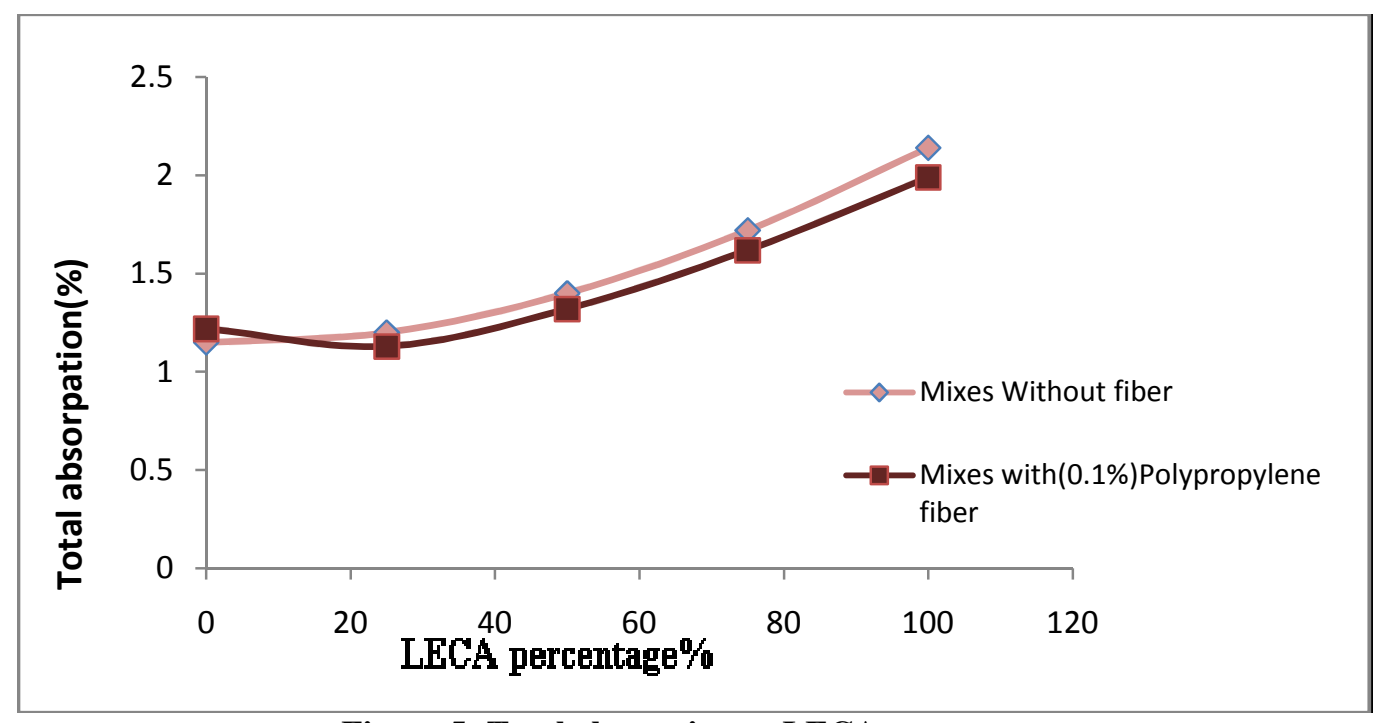

Figure 5: Total absorption vs LECA percentage 


\section{C) Dry Density}

The SCC's dry density has been determined after drying the specimen in the furnace at $\left(110^{\circ} \mathrm{C}\right)$ at age 28 days. Naturally, the dry density has been decreased with the increase in LECA percentage, as shown in Table (6).

The reduction is about $(12.6 \%, 17.7 \%, 20.8 \%, 23.1 \%)$ for LECA replacement percentage $(25 \%, 50 \%, 75 \%$, $100 \%$ ), respectively. The decrease in the oven-dry density is mainly due to the increase in the amount of LECA proportion. Moreover, a lower rate of decrease may occur as a result of higher LECA's water absorption, causing greater loss of moisture while drying the oven, which is consistent with the opinion of [10,41]. Also, it's found that the addition of polypropylene fibre was not effected significantly on the dry density of the concrete. Figure (6) demonstrates the relationship between LECA amount and dry density of concrete.

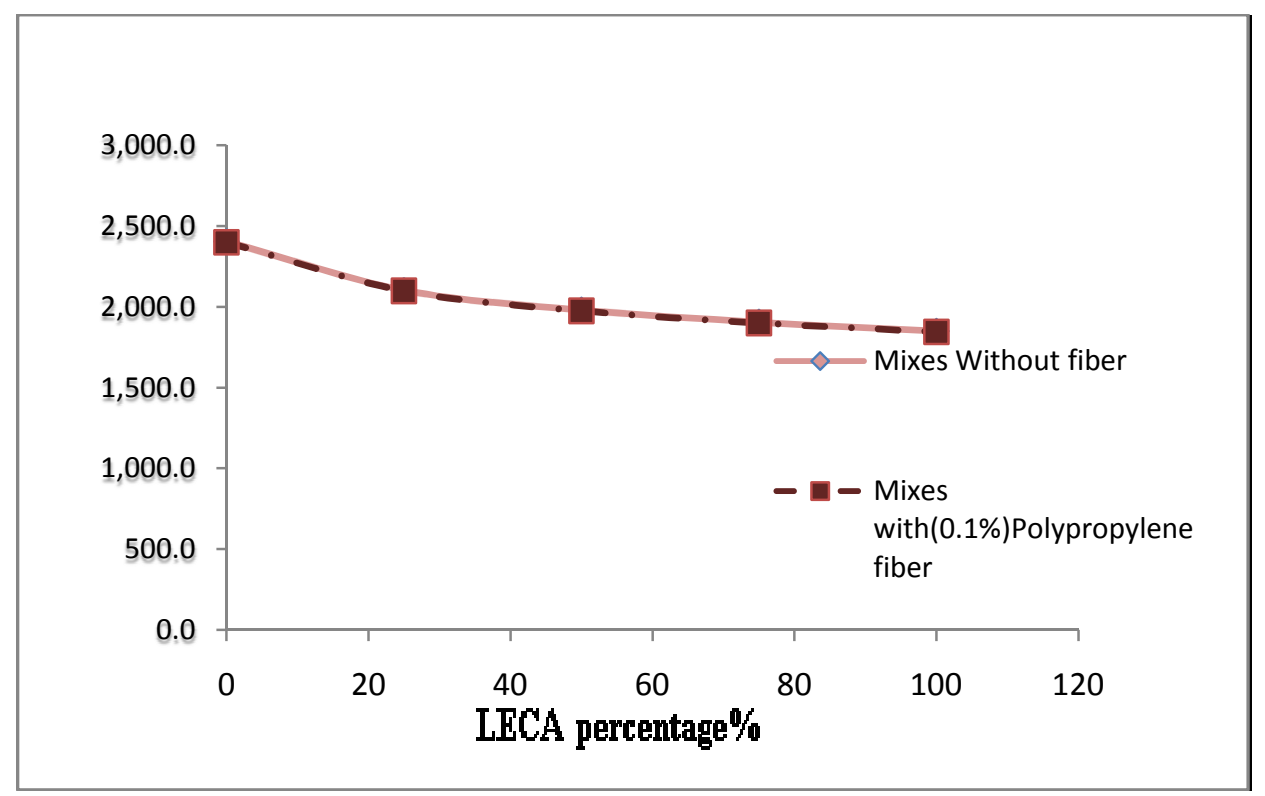

Figure 6: Dry density vs LECA percentage.

Table 6: Result of experimental work

\begin{tabular}{|l|c|c|c|c|c|c|c|c|c|c|c|}
\hline Types of mixes & $\mathbf{L}_{\mathbf{0}}$ & $\mathbf{L}_{\mathbf{2 5}}$ & $\mathbf{L}_{\mathbf{5 0}}$ & $\mathbf{L}_{\mathbf{7 5}}$ & $\mathbf{L}_{\mathbf{1 0 0}}$ & $\mathbf{P L}_{\mathbf{0}}$ & $\mathbf{P L}_{\mathbf{2 5}}$ & $\mathbf{P L}_{\mathbf{5 0}}$ & $\mathbf{P L}_{\mathbf{7 5}}$ & $\mathbf{P L}_{\mathbf{1 0 0}}$ \\
\hline Compressive strength & 50.10 & 43.02 & 40.12 & 36.03 & 30.26 & 50.70 & 43.35 & 40.70 & 36.40 & 30.80 \\
\hline 7 days & 65.14 & 54.83 & 48.23 & 48.23 & 36.01 & 66.09 & 55.85 & 48.40 & 43.00 & 36.80 \\
\hline 28 days & & & & & & & \\
\hline
\end{tabular}




\begin{tabular}{|c|c|c|c|c|c|c|c|c|c|c|}
\hline \multicolumn{11}{|c|}{ Ultra-sonic pulse velocity (U.P.V) at 28 days } \\
\hline $\begin{array}{l}\text { U.P.V value at } \\
\text { 28days }(\mathrm{Km} / \mathrm{s})\end{array}$ & 4.57 & 4.39 & 4.28 & 4.14 & 3.91 & 4.67 & 4.47 & 4.35 & 4.20 & 3.97 \\
\hline $\begin{array}{l}\text { Qualities of } \\
\text { concrete testing } \\
\text { according to } \\
\text { (IAEA, 2002) }\end{array}$ & $\begin{array}{l}0 \\
0 \\
0 \\
8 \\
0\end{array}$ & 0 & 0 & 0 & 0 & 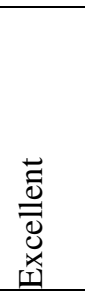 & 0 & 0 & 0 & ט \\
\hline \multicolumn{11}{|l|}{ Total absorption } \\
\hline $\begin{array}{l}\text { Total absorption } \\
\text { (\%) }\end{array}$ & 1.95 & 2.03 & 2.38 & 2.92 & 3.64 & 1.91 & 1.98 & 2.32 & 2.87 & 3.56 \\
\hline \multicolumn{11}{|l|}{ Dry density } \\
\hline $\begin{array}{l}\text { Dry density } \\
\left(\mathbf{K g} / \mathbf{m}^{3}\right)\end{array}$ & 2405 & 2103 & 1980 & 1905 & 1850 & 2400 & 2099 & 1975 & 1900 & 1845 \\
\hline
\end{tabular}

\section{CONCLUSIONS}

Depending on the study experiential work and the interpretation of the consequence, the following conclusions could be drawn;

1. With an increase in the percentage of LECA, the workability was increased with decrease in the filling ability of SCC. Also, the fresh density was increased.

2. With an increase in the percentage of LECA, all mechanical properties of concrete were decreased, absorption was increased, and dry density was decreased as follow:

- Increase in percentage of LECA from (25-100) \% of the NWCA volume. The compressive strength was decreased from $(15.83 \%)$ to $(44.72 \%)$ at 28 days.

- Increase in the percentage of LECA from (25-100) \% of the volume of NWCA. The splitting tensile strength was reduced from $(22.9 \%)$, to $(44.4 \%)$ at 28 days.

- Increase in the percentage of LECA from (25-100)\% of the volume of NWCA. The flexural strength was decreased from(10\%), to $(41.9 \%)$ at 28 days

- Increase in the percentage of LECA from (25-100)\% of the volume of NWCA. The water absorption increased from $(4.1 \%)$ to $(86.67 \%)$ at 28 days

- Increase in the percentage of LECA from (25-100)\% of the volume of NWCA. The dry density was decreased from $(12.6 \%)$ to $(22.7 \%)$ at 28 days

1. The addition of $(0.1 \%)$ polypropylene fibre has a slight effect on the compression strength, but it enhances flexural and splitting tensile strength about (7.8-10.57) \%and (16.9-18.9) \% at 28 days, respectively. 
2. The addition of $(0.1 \%)$ of Polypropylene fibre has no significant impact on the dry density of the concrete, and it causes a slight reduction in water absorption about (1.71-2.52) \% in comparison with the mixes without polypropylene fibre.

This manuscript can be further extended with the feasibility of soft computing where the experimental investigation of the concrete with lightweight self-compacting (LWSCC) can be computed using some advanced models such $[3,4,31,42,43]$.

\section{REFERENCES}

1. Maghsoudi A A, Mohamadpour S H and Maghsoudi M 2011 Mix design and mechanical properties of self compacting light weight concrete

2. Tuama W K, Kadhum M M, Alwash N A, Al-Khafaji Z S and Abdulraheem M S 2020 RPC Effect of Crude Oil Products on the Mechanical Characteristics of Reactive-Powder and Normal-Strength Concrete Period. Polytech. Civ. Eng.

3. Yaseen Z M, Tran M T, Kim S, Bakhshpoori T and Deo R C 2018 Shear strength prediction of steel fiber reinforced concrete beam using hybrid intelligence models: A new approach Eng. Struct. 177 244-55

4. Yaseen Z M, Deo R C, Hilal A, Abd A M, Bueno L C, Salcedo-Sanz S and Nehdi M L 2017 Predicting compressive strength of lightweight foamed concrete using extreme learning machine model Adv. Eng. Softw.

5. Wu Z, Zhang $Y$, Zheng J and Ding Y 2009 An experimental study on the workability of self-compacting lightweight concrete Constr. Build. Mater. 23 2087-92

6. Alwanas A A H, Al-Musawi A A, Salih S Q, Tao H, Ali M and Yaseen Z M 2019 Load-carrying capacity and mode failure simulation of beam-column joint connection: Application of self-tuning machine learning model Eng. Struct. 194 220-9

7. Yaseen Z M, Afan H A and Tran M T 2018 Beam-column joint shear prediction using hybridized deep learning neural network with genetic algorithm IOP Conference Series: Earth and Environmental Science

8. Mussa M H, Abdulhadi A M, Abbood I S, Mutalib A A and Yaseen Z M 2020 Late Age Dynamic Strength of High-Volume Fly Ash Concrete with Nano-Silica and Polypropylene Fibres Crystals 10243

9. Vakhshouri B and Nejadi S 2016 Mix design of light-weight self-compacting concrete Case Stud. Constr. Mater. 4 1-14

10. Al-Khafaji Z S and Falah M W 2020 Applications of high density concrete in preventing the impact of radiation on human health J. Adv. Res. Dyn. Control Syst. 12

11. Madandoust R, Ranjbar M M and Yasin Mousavi S 2011 An investigation on the fresh properties of self-compacted lightweight concrete containing expanded polystyrene Constr. Build. Mater. 25 3721-31

12. Papanicolaou C G and Kaffetzakis M I 2011 Lightweight Aggregate Self-Compacting Concrete: State-of-the-Art \& Pumice Application J. Adv. Concr. Technol. 9 15-29

13. Lotfy A, Hossain K M A and Lachemi M 2014 Application of statistical models in proportioning lightweight self-consolidating concrete with expanded clay aggregates Constr. Build. Mater. 65 450-69

14. Shi C 2005 Design and application of self-compacting lightweight concrete SCC'2005-China - 1st Int. Symp. Des. Perform. Use Self-Consolidating Concr.

15. Specification I 2001 No. 45/1984, Aggregates from Natural Sources for Concrete and Construction Natl. Cent. Constr. Lab. Res. Baghdad 
16. Anon 1995 Abstract of: Guide for the Use of Silica Fume in Concrete (ACI 234R) ACI Mater. J. 92

17. Zainab O. Al Masoodi Zainab Al Khafaji, Hassnen M Jafer, Anmar Dulaimi W A 2017 The effect of a high alumina silica waste material on the engineering properties of a cement-stabilised soft soil The 3rd BUiD Doctoral Research Conference (Dubai, AUE)

18. Anon Specification for Silica Fume Used in Cementitious Mixtures

19. Anon 2017 AN EXPERIMENTAL STUDY ON PROPERTIES OF PERVIOUS CONCRETE WITH PARTIAL REPLACEMENT OF CEMENT BY FLY ASH Int. J. Mod. Trends Eng. Res. 4 40-7

20. Materials) A (American S for T and 2005 C494: Standard specification for chemical admixtures for concrete.

21. Group S-C C E P 2005 The European guidelines for self-compacting concrete: Specification, production and use (International Bureau for Precast Concrete (BIBM))

22. Widodo S 2012 Fresh and hardened properties of Polypropylene fiber added Self-Consolidating Concrete Int. J. Civ. Struct. Eng. 3 85-93

23. Norma A 1999 C109/C109M, Standard Test Method for Compressive Strength of Hydraulic Cement Mortars (Using 2-in. or [50-mm] Cube Specimens), West Conshohocken, Pa EE. UU.) Am. Soc. Test. Mater.

24. Standard A C496/C496M-17 (2017) Standard test method for splitting tensile strength of cylindrical concrete specimens ASTM Int. West Conshohocken, PA

25. Standard A 2016 C78/C78M-15b, 2016, “ Stand. Test Method Flexural Strength Concr. (Using Simple Beam with Third-Point Loading)", ASTM Int. West Conshohocken, PA

26. Anon Test Method for Density and Void Content of Hardened Pervious Concrete

27. ASTM C 2012 Standard test method for density and void content of hardened pervious concrete Annu. B. ASTM Stand. Am. Soc. Test. Mater.

28. Standard A 2002 C597-02 ASTM Stand. test method pulse Veloc. through Concr. West Conshohocken Am. Soc. Test. Mater.

29. Lorenzi A, Tisbierek F T and Silva L C P 2007 Ultrasonic pulse velocity análysis in concrete specimens IV Conferencia Panamericana de END, Buenos Aires

30. Dilli M E, Atahan $H N$ and Şengül C 2015 A comparison of strength and elastic properties between conventional and lightweight structural concretes designed with expanded clay aggregates Constr. Build. Mater. $101260-7$

31. Ashrafian A, Shokri F, Amiri M J T, Yaseen Z M and Rezaie-Balf M 2020 Compressive strength of Foamed Cellular Lightweight Concrete simulation: New development of hybrid artificial intelligence model Constr. Build. Mater. 230117048

32. Dr. Abdullah Jabar Hussain A Z S A-K 2020 The Fields of Applying the Recycled and Used Oils by the Internal Combustion Engines for Purposes of Protecting the Environment against Pollutions J. Adv. Res. Dyn. Control Syst. 12 666-70

33. Bogas J A and Gomes A 2013 Compressive behavior and failure modes of structural lightweight aggregate concrete Characterization and strength prediction Mater. Des. 46 832-41

34. Mirza F A and Abdel-Rhaman A G 2016 Performance of Polypropylene Fiber Reinforced Self-Compacting Lightweight Concrete in Hardened State Fourth International Conference on Sustainable Construction Materials and Technologies ttp://www. claisse. info/Proceedings. htm SCMT4 Las Vegas, USA

35. Abutaha F, Abdul Razak H and Kanadasan J 2016 Effect of palm oil clinker (POC) aggregates on fresh and hardened properties of concrete Constr. Build. Mater. $112416-23$ 
36. Shendge A, Narule G and Walke S 2017 Effect of Mixed Fiber Reinforced Concrete Exposed to Different Exposure Condition

37. Alexandre Bogas J, Gomes M G and Real S 2014 Capillary absorption of structural lightweight aggregate concrete Mater. Struct. 48 2869-83

38. Real S, Bogas $J$ A and Pontes $J 2015$ Chloride migration in structural lightweight aggregate concrete produced with different binders Constr. Build. Mater. 98 425-36

39. Suhaendi S L and Horiguchi T 2006 Effect of short fibers on residual permeability and mechanical properties of hybrid fibre reinforced high strength concrete after heat exposition Cem. Concr. Res. 36 1672-8

40. Chou T W, Kelly A and Okura A 1985 Fibre-reinforced metal-matrix composites Composites 16 187-206

41. Rashad A M 2018 Lightweight expanded clay aggregate as a building material - An overview Constr. Build. Mater. 170 $757-$ 75

42. Al-Musawi A A, Alwanas A A H, Salih S Q, Ali Z H, Tran M T and Yaseen Z M 2020 Shear strength of SFRCB without stirrups simulation: implementation of hybrid artificial intelligence model Eng. Comput.

43. Keshtegar B, Bagheri M and Yaseen Z M 2019 Shear strength of steel fiber-unconfined reinforced concrete beam simulation: Application of novel intelligent model Compos. Struct. 